\title{
Mental retardation, periventricular white matter hyperintensity on brain magnetic resonance imaging, retinitis pigmentosa, optic atrophy: A new genetic syndrome
}

\author{
Aamir Jalal Al-Mosawi*12 \\ 1-Advisor in Pediatrics and Pediatric Psychiatry Children Teaching Hospital of Baghdad Medical City \\ 2-Head, Iraq Headquarter of Copernicus Scientists International Panel Baghdad, Iraq \\ E-mail:almosawiAJ@yahoo.com \\ Submitted: 26 April 2020 \\ Approved: 8 May 2020 \\ Published: 12 May 2020
}

How to cite this article: Al-Mosawi AJ. Mental retardation, periventricular white matter hyperintensity on brain magnetic resonance imaging, retinitis pigmentosa, optic atrophy: A new genetic syndrome. G Med Sci. 2020; 1(1): 010-012.

https://www.doi.org/10.46766/thegms.pedia.20042501

Copyright: (c) 2020 Aamir J. This is an open access article distributed under the Creative Commons Attribution License, which permits unrestricted use, distribution, and reproduction in any medium, provided the original work is properly cited.

\begin{abstract}
Background: Leukodystrophy is a typical example of progressive cerebral periventricular white matter brain disorders. The occurrence of leukodystrophic white matter on magnetic resonance imaging in with children non-progressive poorly defined non-specific disorders has been recognized.

Patients and methods: A fourteen-year old boy with mental retardation with no speech and severe visual impairment was seen and studied at the pediatric neuropsychiatry clinic of the Children Teaching Hospital of Baghdad Medical City during the year 2019. Results: A.M is a fourteenyear old boy who was born to consanguineous parents and had experienced delayed development and serious impairment in vision very early in life. At the age of fourteen years, was able to walk, but he had psychomotor retardation with poor attention to the environment and was totally dependent on his mother. He was not saying any word, but hearing assessment showed normal hearing. Eye examination showed bilateral retinitis pigmentosa and pale optic discs. Chromosomal study showed normal karyoype. Brain magnetic resonance imaging showed bilateral confluent periventricular hyperintensities described by radiologists as leukodystrophic changes. The ventricles and the cerebrospinal fluids were normal.
\end{abstract}

Conclusion: The occurrence of a non-progressive mental retardation syndrome associated with periventricular white matter hyperintensity on brain magnetic resonance imaging, retinitis pigmentosa, optic atrophy, and no speech development despite normal hearing in a one patient is described in this paper. The early onset of the disorder and the association with retinitis suggests a new genetic syndrome.

Key words: Mental retardation, retinitis pigmentosa, leukodystrophy-like white matter abnormalities, MRI

\section{Introduction}

Magnetic resonance imaging has been increasingly used in the diagnosis of childhood periventricular white matter brain disorders that are not always seen with x-ray CT scans. Leukodystrophy is a typical example of progressive cerebral periventricular white matter brain disorders. Magnetic resonance findings in leukodystrophy include T2 weighted (spin-echo) images showing prominently asymmetric involvement of cerebral white matter, especially in periventricular white matter and visual radiations. Calculated T1 values are elevated in the children with leukodystrophy [1]. Other disorders that can be associated with periventricular hyperintensity include multiple sclerosis which is rarely seen during childhood, and hydrocephalus [2]. In 1996 Kristjánsdóttir et al from Sweden studied 78 children with white matter abnormalities on magnetic resonance imaging,

13 patients with an apparently leukodystrophic white matter had non-progressive poorly defined non-specific disorders [3]. 


\section{Patients and methods}

A fourteen-year old boy with mental retardation with no speech and severe visual impairment was seen and studied at the pediatric neuropsychiatry clinic of the Children Teaching Hospital of Baghdad Medical City during the year 2019.

\section{Results}

A.M is a fourteen-year old boy who was born to consanguineous parents and had experienced delayed development and serious impairment in vision very early in life. At the age of fourteen years, was able to walk, but he had psychomotor retardation with poor attention to the environment (Figure-1) and was totally dependent on his mother. He was not saying any word, but hearing assessment showed normal hearing. The boy was underweight, his weight was 24 kilograms. He didn't show clinical evidence of neuropathy and was responding to painful stimuli by crying. Eye examination showed bilateral retinitis pigmentosa and pale optic discs. Chromosomal study showed normal karyoype. Brain magnetic resonance imaging showed bilateral confluent periventricular hyperintensities described by radiologists as leukodystrophic changes. The ventricles and the cerebrospinal fluids were normal (Figure-2).

The boy was treated initially with intramuscular cerebrolysin $(5 \mathrm{ml}$ every third day, 10 doses over one month) and nutritional support. After treatment (Figure-3), the mother reported improvement in psychomotor retardation and nutrition.

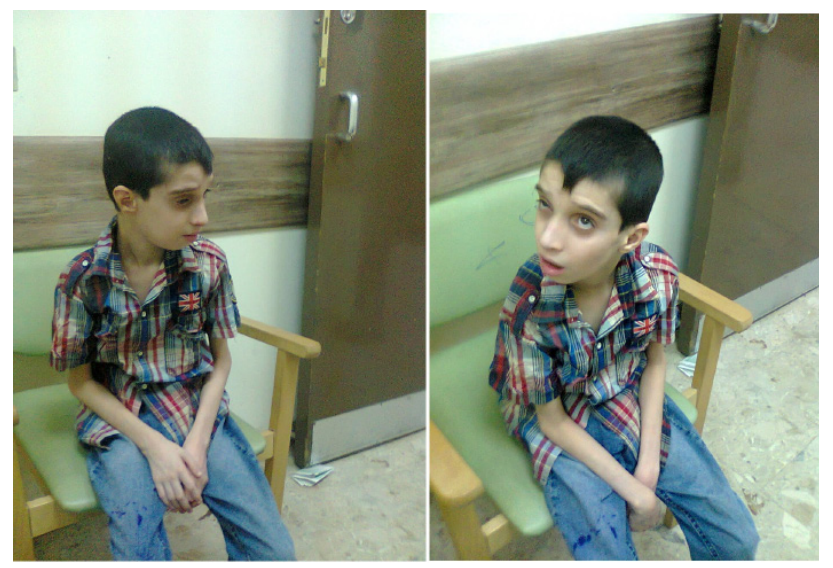

Figure 1: At the age of fourteen years, the boy was able to walk, but he had psychomotor retardation with poor attention to the environment

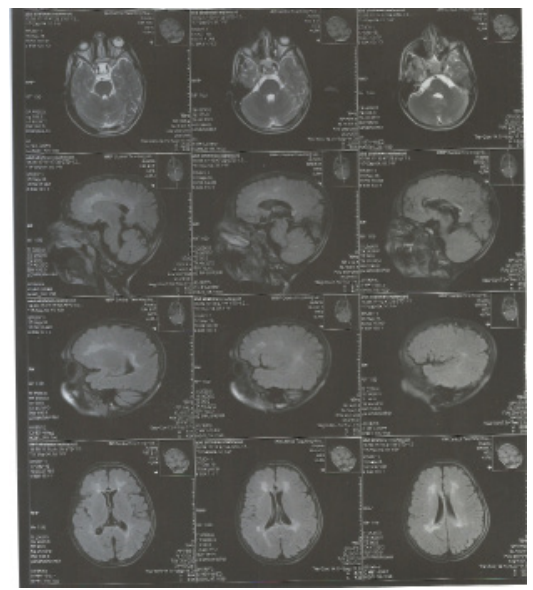

Figure 2A: Brain magnetic resonance imaging showed bilateral confluent periventricular hyperintensities described by radiologists as leukodystrophic changes

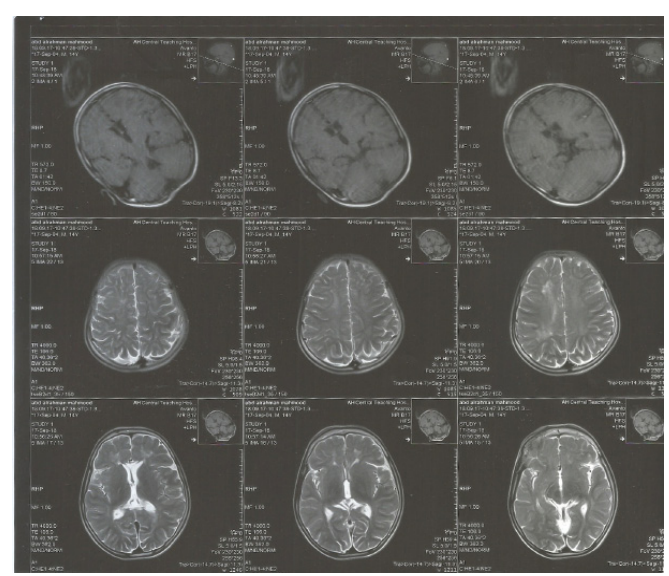

Figure 2B: Brain magnetic resonance imaging showed bilateral confluent periventricular hyperintensities described by radiologists as leukodystrophic changes

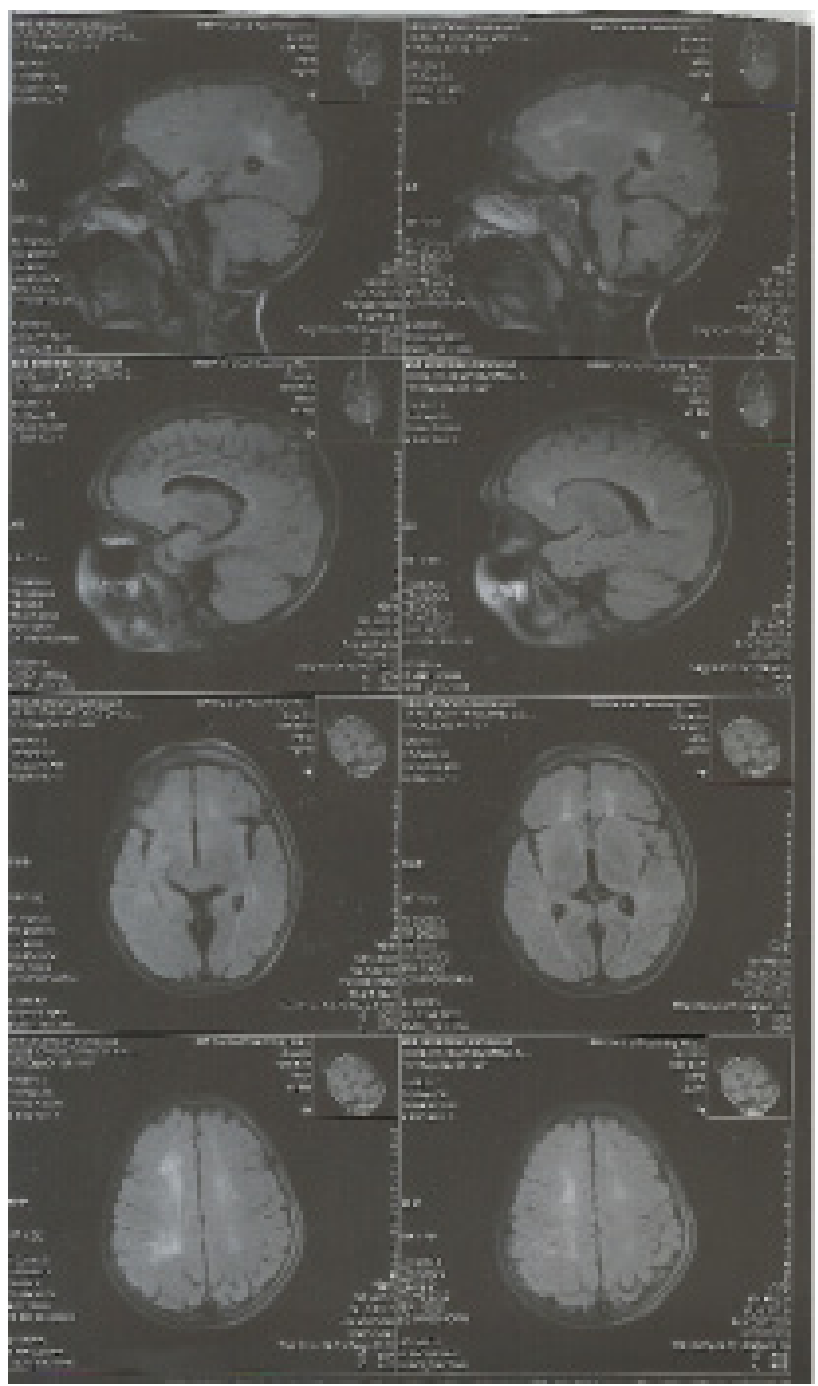

Figure 2C: Brain magnetic resonance imaging showed bilateral confluent periventricular hyperintensities described by radiologists as leukodystrophic changes 


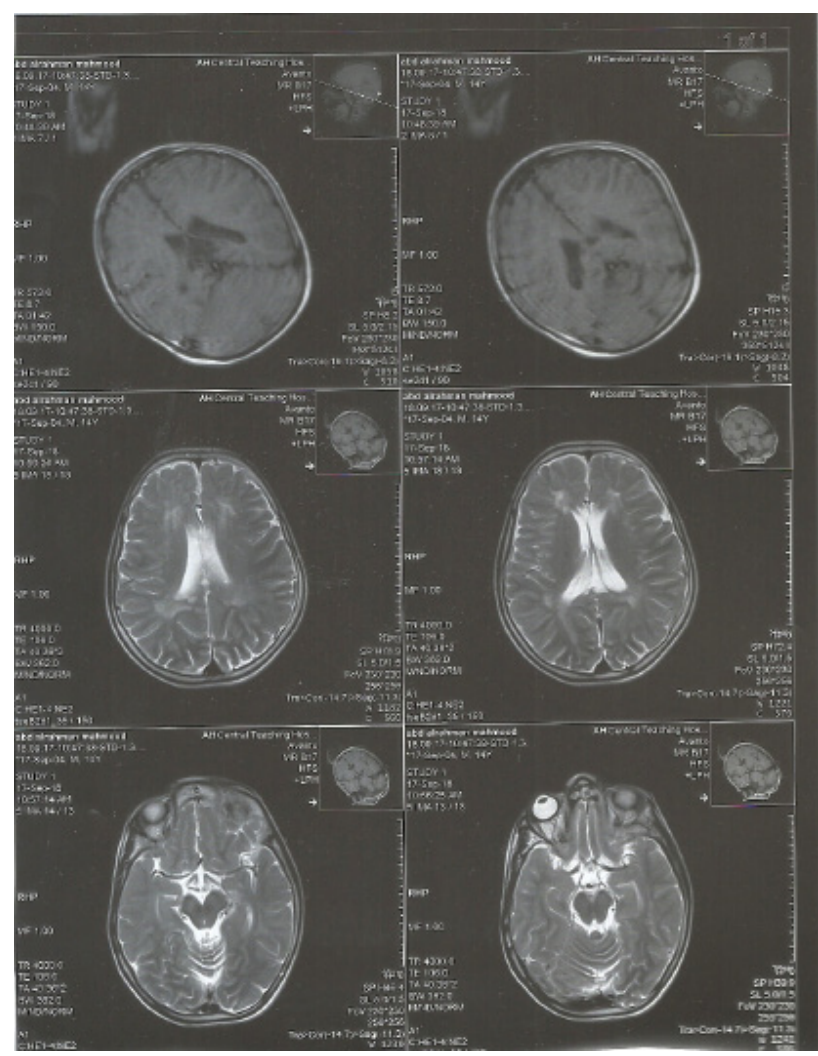

Figure 2D: Brain magnetic resonance imaging showed bilateral confluent periventricular hyperintensities described by radiologists as leukodystrophic changes

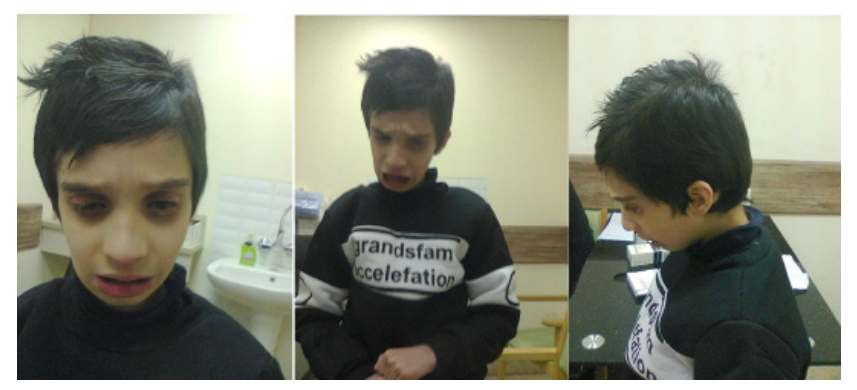

Figure 3: after treatment, the mother reported improvement in psychomotor retardation and nutrition

\section{Discussion}

In 2000, Kristjánsdóttir, Uvebrant, and Wiklund from Sweden reported 15 children with non-specific clinical neurologic had leukodystrophylike white matter abnormalities on MRI, and had non-progressive clinical presentation and course. The patients of Kristjánsdóttir and colleagues had early onset of symptoms within the first year of life, most often presenting as general developmental delay and hypotonia. Laterappearing signs were spasticity and ataxia and as a rule severe learning and motor disabilities. Serious ocular abnormalities were frequent [4].

The patient was initially treated with a course of intramuscular cerebrolysin based on our extensive published experience with use of cerebrolysin in various neuropsychiatric and genetic brain disorders including mental retardation, cerebral palsy, brain atrophy, kernicterus and Rett syndrome [5-12]

\section{Conclusion}

The occurrence of a non-progressive mental retardation syndrome associated with periventricular white matter hyperintensity on brain magnetic resonance imaging, retinitis pigmentosa, optic atrophy, and no speech development despite normal hearing in a one patient is described in this paper. The early onset of the disorder and the association with retinitis suggests a new genetic syndrome.

\section{References}

1-Young RS, Osbakken MD, Alger PM, Ramer JC, Weidner WA, Daigh JD. Magnetic resonance imaging in leukodystrophies of childhood. Pediatr Neurol 1985 Jan-Feb; 1(1):15-9. PMID: 3880385.

2-Zimmerman RD, Fleming CA, Lee BC, Saint-Louis LA, Deck MD. Periventricular hyperintensity as seen by magnetic resonance: prevalence and significance. AJR Am J Roentgenol. 1986 Mar; 146(3):443-50. PMID: 3484859 .

3-Kristjánsdóttir R, Uvebrant P, Hagberg B, Kyllerman M, Wiklund LM, Blennow G, Flodmark O, Gustavsson L, Ekholm S, Månsson JE. Disorders of the cerebral white matter in children. The spectrum of lesions. Neuropediatrics 1996 Dec; 27(6):295-8. PMID: 9050046.

4-Kristjánsdóttir R, Uvebrant P, Wiklund LM. Clinical characteristics of children with cerebral white matter abnormalities. Eur J Paediatr Neurol 2000; 4(1):17-26. PMID: 10701100.

5-Al-Mosawi AJ. A novel therapeutic approach for idiopathic mental retardation. 1st ed., Saarbrücken; LAP Lambert Academic Publishing: 2018 (ISBN: 978-613-9-81808-2).Al-

6-Al-Mosawi AJ. The etiology of mental retardation in Iraqi children. SunKrist Journal of Neonatology and Pediatrics.2019; 1(1):1-9.

7-Al-Mosawi AJ. New Therapies for the treatment of spastic cerebral palsy. Med J Clin Trials Case Stud 2019; 3(2): 000209. USA.

8-Al-Mosawi AJ. A new therapeutic approach for the treatment of brain atrophy. 1st ed., Saarbrücken; LAP Lambert Academic Publishing: 2017 (ISBN: 978-620-2-07438-4).

9-Al-Mosawi AJ. The novel use of cerebrolysin and citicoline in the treatment of kernicterus. Online Journal of Neurology and Brain Disorders (ISSN: 2637-6628) 2019; 3 (1): 208-212.

10-Al-Mosawi AJ. New therapies for Rett syndrome. J Bio Innov 2019; 8(3): 301-307.

11-Al-Mosawi AJ. The pattern of cerebral palsy in Iraqi children. Med Life Clin. 2019; 1(1):1001.

12-Al-Mosawi AJ. The use of piracetam and cerebrolysin in the treatment of agenesis of corpus callosum with colpocephaly. EC clinical and medical case reports 2020; 3(1): 01-05.

\section{Acknowledgement}

The author would like to express his gratitude for the parents who accepted the publication of the photos of their child. 